\title{
A IRRITAÇÃO DO SISTEMA DA ECONOMIA SOBRE O SISTEMA DO DIREITO: UMA ANÁLISE EMPÍRICA ACERCA DA REFORMA DA PREVIDÊNCIA
}

\author{
THE IRRITATION OF THE ECONOMY'S SYSTEM ON THE LAW'S SYSTEM: AN \\ EMPIRICAL ANALYSIS ABOUT THE REFORM OF THE PENSION
}

JOVANA SOTTILI 1

Recebido em 19/09/2017

Aprovado em 08/02/2018

RESUMO: O direito previdenciário é um direito de segunda geração e, indiscutivelmente, fundamental para atingir os objetivos do Estado, previstos no art. 3, III da Constituição Federal. Por isso, analisar o paradoxo da irritação causada pelo sistema da economia no sistema do direito previdenciário é o escopo principal deste artigo, através de um viés teórico e científico. Busca-se, ainda, verificar quais seriam os limites da influência - se essa é possível e aceitável - do ambiente nos direitos dos trabalhadores, qual a possível solução, advinda do direito comparado, a ser adotada para evitar o prejuízo irreversível para o bem-estar social, a afetação do meio no direito previdenciário. Como resultado da pesquisa teórica e empírica notou-se que existe um exemplo prático de Reforma Previdenciária no Chile, que pode ser utilizado como parâmetro para o Brasil.

PAlAVRAS-CHAVE: Teoria Sistêmica. Reforma da Previdência. Constituição. Modelo Chileno. Caraterística Autopoiética do Direito.

ABSTRACT: The Social security law is a second generation right and, undoubtedly, fundamental to achieve the objectives of the State, previse in article 3, III of the Federal Constitution. Therefore, analyzing the paradox of the irritation caused by the economics' system in the social security law's system is the main scope of this article, through a theoretical and scientific bias. It is also sought to verify the limits of the influence - if it's possible and acceptable - of the environment on workers' rights, what is the possible solution, from comparative law, to be adopted to avoid irreversible damage to the social well- being, the affectedness of the environment in social security law. As a result of the theoretical and empirical research it was observed that there is a practical example of Social Security Reform in Chile, which can be used as a parameter for Brazil.

KEYWORDS: Systemic Theory. Social Security Reform. Constitution. Chilean Model. Autopoietic Characteristics of Law.

\footnotetext{
1 Possui graduação em Direito pela Universidade de Caxias do Sul (2015), com estudo de conclusão na área de Direito Constitucional e Previdenciário. É pós-graduada em Direito Previdenciário pela Escola Superior Verbo Jurídico (2017), com estudo de conclusão na área de Direito Previdenciário, Sociologia Jurídica, Filosofia e Direito Constitucional.
} 


\section{INTRODUÇÃO}

A atual crise econômica trouxe, junto de si, inúmeras propostas de alterações legislativas capazes de afetar o direito dos cidadãos. Direitos que foram conquistados através de uma evolução social de inclusão e de respeito à Constituição Federal.

Em razão do presente, o objetivo da pesquisa é estudar a irritação ocasionada pelo sistema da economia - por meio do instrumento da Reforma da Previdência, cujo texto está inserido na PEC 287/2016 - sobre o sistema do direito, em particular sobre o subsistema do direito previdenciário, e as suas possíveis implicações. Tudo através do viés da Teoria Sistêmica.

Busca-se, pois, investigar qual seria a consequência prática da interferência do meio no subsistema do direito previdenciário. Em outras palavras, o que restaria do subsistema do direito previdenciário caso fosse admitida a intervenção do sistema da economia em sua estrutura interna.

Através de uma análise empírica, verifica-se, por fenecimento, uma solução para o problema econômico que não signifique afrontar as garantias fundamentais, nem retroceder em termos de direitos sociais. Para tanto, resta utilizado como parâmetro um modelo que já foi e ainda é alvo de muita polêmica, a Previdência Chilena.

\section{PROPOSTA DA REFORMA PREVIDENCIÁRIA}

Primeiramente, para analisar a conjuntura da Reforma Previdenciária, mister evocar as espécies vigentes de aposentadorias no Regime Geral da Previdência Social, as quais dependem da circunstância em que o segurado exerce a atividade laborativa ou, se deixou de exercê-la, no caso dos benefícios por incapacidade.

De acordo com a Lei de Benefícios ( Lei $n^{\circ}$ 8.213/91) e a Constituição Federal de 1988, em síntese, assim são definidas as aposentadorias:

a) Aposentadoria por Invalidez: é direito do segurado que, estando ou não em auxíliodoença, encontra-se incapaz de exercer atividades laborativas e insuscetível de reabilitação. Caso a lesão ou a doença tenham sido diagnosticadas antes da filiação à Previdência Social, 
considera-se preexistência, e o segurado não fará jus ao benefício, salvo, tratando-se de caso de agravamento. A carência exigida para concessão do benefício é de doze contribuições, ou seja, um ano, exceto na hipótese do artigo 26 da Lei $n^{\circ}$ 8.2132, que independe de carência.

b) Aposentadoria por Idade Urbana: é direito do trabalhador urbano a partir dos 65 anos, se homem e 60 anos, se mulher, desde que implementada a carência necessária. A Lei ${ }^{\circ}$ 8.213/91 trouxe a exigência da carência de cento e oitenta contribuições mensais, portanto, tal requisito só é obrigatório para os segurados que se filiaram ao Regime Geral da Previdência Social após 24 de julho de 1991, data de vigência do referido diploma legal.

c) Aposentadoria por Idade Rural: é concedida ao trabalhador rural a partir dos 60 anos, se homem e 55 anos, se mulher, desde que cumprida a carência atual exigida de 15 (quinze) anos, trabalhados na agricultura, ou, se filiado à Previdência Social antes da edição da Lei de Benefícios, possuir a prerrogativa da regra de transição estabelecida pela Tabela Progressiva de Carência. Veja-se que não há exigência de efetiva contribuição, mas apenas de comprovação da atividade rural. Nesta espécie de benefício, conforme se percebe, há uma redução de cinco anos no requisito etário com relação à Aposentadoria por Idade Urbana, anteriormente citada.

d) Aposentadoria da Pessoa com Deficiência: foi incluída no rol de benefícios do Regime Geral da Previdência Social, pela Lei Complementar $n^{\circ} 142$, de 8 de maio de 2013. A pessoa com deficiência é considerada, conforme artigo $2^{\circ}$ do diploma legal, aquela que tem impedimentos de longo prazo de natureza física, mental, intelectual ou sensorial.

Segundo artigo $3^{\circ}$ da Lei Complementar $n^{\circ} 142$ :

Art. $3^{\circ}$ É assegurada a concessão de aposentadoria pelo RGPS ao segurado com deficiência, observadas as seguintes condições:

I - aos 25 (vinte e cinco) anos de tempo de contribuição, se homem, e 20 (vinte) anos, se mulher, no caso de segurado com deficiência grave;

2 Lei 8.213/1991. Art. 26. Independe de carência a concessão das seguintes prestações:

I - pensão por morte, auxílio-reclusão, salário-família e auxílio-acidente;

II - auxílio-doença e aposentadoria por invalidez nos casos de acidente de qualquer natureza ou causa e de doença profissional ou do trabalho, bem como nos casos de segurado que, após filiar-se ao Regime Geral de Previdência Social, for acometido de alguma das doenças e afecções especificadas em lista elaborada pelos Ministérios da Saúde e do Trabalho e da Previdência Social a cada três anos, de acordo com os critérios de estigma, deformação, mutilação, deficiência, ou outro fator que the confira especificidade e gravidade que mereçam tratamento particularizado;

III - os benefícios concedidos na forma do inciso I do art. 39, aos segurados especiais referidos no inciso VII do art. 11 desta Lei;

IV - serviço social;

V - reabilitação profissional;

VI - salário-maternidade para as seguradas empregada, trabalhadora avulsa e empregada doméstica. 
II - aos 29 (vinte e nove) anos de tempo de contribuição, se homem, e 24 (vinte e quatro) anos, se mulher, no caso de segurado com deficiência moderada;

III - aos 33 (trinta e três) anos de tempo de contribuição, se homem, e 28 (vinte e oito) anos, se mulher, no caso de segurado com deficiência leve; ou IV - aos 60 (sessenta) anos de idade, se homem, e 55 (cinquenta e cinco) anos de idade, se mulher, independentemente do grau de deficiência, desde que cumprido tempo mínimo de contribuição de 15 (quinze) anos e comprovada a existência de deficiência durante igual período.

Parágrafo único. Regulamento do Poder Executivo definirá as deficiências grave, moderada e leve para os fins desta Lei Complementar.

e) Aposentadoria Especial: para alcançá-la, além do tempo de trabalho é necessário comprovar a efetiva exposição (habitual e permanente) a agentes nocivos à saúde, químicos, físicos ou biológicos, ou associação de agentes prejudiciais pelo período exigido para concessão do benefício em 15, 20 ou 25 anos, de acordo com o artigo 57 da Lei ${ }^{\circ}$. 8.213/91. Esta espécie de benefício visa ressarcir o empregado pela exposição a condições especiais. Por isso, o requisito diferenciado de 25, 20 ou 15 anos de atividade especial. Considerando, também, a possibilidade de conversão de períodos individuais de trabalho para tempo comum, objetivando a aposentadoria por tempo de contribuição.

f) Aposentadoria por Tempo de Contribuição: é devida ao segurado que completar além da carência o tempo mínimo de contribuição, se homem, 35 anos de contribuição, se mulher, 30 anos. Pode ser integral ou proporcional.

Esta última espécie de aposentadoria vem sendo, há muito tempo, criticada pelos doutrinadores, dentre eles, Ivan Kertzman e Wagner Balera; sob o fundamento de que não se coaduna com o objetivo da Previdência Social que é a cobertura dos riscos sociais.

Para Ivan Kertzman ${ }^{3}$ “[...] o fato de o segurado ter contribuído por determinado número de anos não pressupõe, necessariamente, que ele não tenha mais condições de exercer a sua atividade".

Wagner Balera4 entende que "cada risco social considerado relevante deve ser contemplado com um benefício previdenciário que garanta a sua cobertura, ou seja, o sistema deve atuar na desordem social".

Nessa linha foi que a imposição de uma idade mínima para concessão desta espécie de benefício previdenciário foi alvo de inúmeras propostas rejeitadas pelo Congresso Nacional

\footnotetext{
3 KERTZMAN, Ivan. Curso Prático de Direito Previdenciário. 8. ed. Salvador: Juspodivm, 2011. p. 382.

4 BALERA, Wagner. Sistema de Seguridade Social. 3. ed. São Paulo: LTr, 2003. p. 13.
} 
durante a discussão da Reforma Previdenciária, de 1998. Isso porque, conforme leciona Miguel Horvath Júnior5,

embora tecnicamente o tempo de contribuição não é um risco, mas sim uma certeza de que ao final do prazo estipulado legalmente, em havendo as contribuições regulares, será concedida a aposentadoria, o risco velhice encontra-se presumido em tal prestação, pois a idéia é de que após 35 anos de contribuição para os homens e 30 anos para as mulheres, o segurado esteja desgastado para continuar exercendo suas atividades.

Atualmente, em meio à crise econômica e política, uma proposta de Emenda à Constituição, com esse novo intento, foi encaminhada para análise do Congresso Nacional, PEC 287/2016.

O governo federal já assumiu a posição de condicionar o ajuste fiscal à reforma da previdência ${ }^{6}$. A intenção é fazer uma poupança de 678 bilhões em dez anos de vigência da reforma. $^{7}$

Veja-se algumas das principais mudanças previstas no texto da PEC citada:

(a) a condição da implementação de 65 (sessenta e cinco) anos de idade para poder se aposentar, tanto para homens, quanto para mulheres, cumulativamente, a exigência do cumprimento de, pelo menos, 25 anos de tempo de contribuição;

(b) para o segurado com deficiência, que exerce atividade de risco ou cujas atividades sejam especiais prejudicando a saúde - vedado enquadramento por categoria profissional ou ocupação - a redução do tempo será de, no máximo, 10 (dez) anos para o requisito etário e de, no máximo, 5 (cinco) anos para o requisito tempo de contribuição;

(c) a obrigatoriedade de contribuição efetiva ao Regime Geral da Previdência Social para o produtor rural, segurado especial, ainda que através de alíquota favorecida;

(d) o cálculo do salário de benefício das aposentadorias - salvo da aposentadoria por invalidez decorrente, exclusivamente de acidente de trabalho - corresponderá a $51 \%$ da média dos salários de contribuição acrescidos de 1 ponto percentual para

\footnotetext{
5 HORVATH, Miguel. Direito Previdenciário. 5. ed. São Paulo: QuartierLatin, 2005.

6 BONFATTI, Cristiane et al. Ajuste só estará completo com reforma da Previdência, afirma Temer. Valor Econômico, 21/11/2016. Disponível em: $<$ http://www.valor.com.br/politica/4782125/ajuste-so-estara-completocom-reforma-da-previdencia-afirma-temer> Acesso em: 23/03/2017.
}

7 ALEGRETTI, Laís. Reforma da Previdência pode gerar economia de R\$ 678 bi, diz governo. Folha de São Paulo, 05/12/2016. Disponível em: <http://www1.folha.uol.com.br/mercado/2016/12/1838400-reforma-daprevidencia-pode-gerar-economia-de-r-678-bi-diz-governo.shtml $>$ Acesso em: 20/01/2017. 
cada ano de contribuição ao RGPS, até o limite de $100 \%$, respeitado o teto máximo da Previdência Social.

(e) na pensão por morte, o salário de benefício será equivalente a uma cota familiar, de $50 \%$, acrescida de 10 pontos percentuais por dependente até o limite de $100 \%$ do valor da aposentadoria que o segurado percebia ou daquela que teria direito se fosse aposentado por incapacidade permanente na data do óbito. As cotas dos dependentes não serão reversíveis aos demais beneficiários.

Sintetizando, a aposentadoria por tempo de contribuição, como a conhecemos hoje, será extinta, caso a proposta seja aprovada, e a aposentadoria por idade, significativamente reformulada, já que, de qualquer forma, a condição mínima para a percepção do benefício será o implemento de 65 (sessenta e cinco) anos de idade, sem distinção de gênero, além do plus que a Reforma traz, da exigência de um tempo mínimo de contribuição.

\section{ECONOMIA X DIREITO PREVIDENCIÁRIO}

Conforme já abordado, a reforma previdenciária é, basicamente, a única medida em discussão que tem como escopo promover o ajuste fiscal do país 8 . Assim, a proposta surgiu do apelo econômico.

Esta circunstância remete à várias indagações: (a) deve a economia irritar o direito ao ponto de transmutá-lo para fins, exclusivamente, financeiros?; (b) os direitos previdenciários atuais, conquistados a muito custo, devem ser extintos em prol do dito equilíbrio macroeconômico? (c) a Constituição Federal deve ser alterada, tão radicalmente, a ponto de reduzir, consideravelmente, o alcance da cobertura previdenciária?; (d) a alteração, tal como proposta, se coaduna com os princípios constitucionais e objetivos fundamentais da República?

Uma das teorias que pode ser utilizada para explicar a batalha travada entre a economia e o direito previdenciário, atualmente, nasceu na década de 80 , com os elementos e conceitos trazidos por Nikles Luhmann.

\footnotetext{
8 OLIVEIRA, Gesner. Sem reforma da previdência não há ajuste fiscal. Uol Economia, 31/01/2017. Disponível em: $\quad<$ http://gesneroliveira.blogosfera.uol.com.br/2017/01/31/sem-reforma-da-previdencia-nao-ha-ajuste-fiscal/> Acesso em: 23/03/2017.
} 
A teoria luhmanniana incorpora às ciências sociais conceitos multidisciplinares, tais como a biologia, a física, a psicologia, a economia, a teoria da comunicação, a cibernética, utilizando-os no estudo de fenômenos sociais. ${ }^{9}$ Sendo capaz de elucidar como se desenvolve, ou deveria, a relação entre o sistema da economia e do direito.

Para Luhmann ${ }^{10}$, a sociedade é formada de diversos subsistemas sociais, cada qual com sua finalidade, sendo que o direito e a economia se tratam de dois desses subsistemas.

$\mathrm{Na}$ teoria sistêmica, os subsistemas possuem característica autopoiética. Um sistema autopoiético é aquele que é suficiente em si mesmo e, a partir de suas próprias estruturas, se reproduz e evolui, sem jamais suprimir a si próprio. Então, para Luhmann, não há como os sistemas se reproduzirem de outra forma que não através de suas próprias estruturas 11 . Conforme explica Luhmann:

O sistema é aberto cognitivamente para ser estimulado através de ruídos ou perturbações oriundas do ambiente. Com isso, obtém a energia necessária para alimentar suas operações internas. Não é aberto no sentido da teoria tradicional, já que a relação entre as provocações do entorno e as respostas do sistema não é causal e linear (a cada perturbação uma resposta do sistema); também não é aberto nos termos do modelo cibernético de input/ output (a cada perturbação registrada na memória do sistema uma resposta). Mais bem, trata-se de uma abertura seletiva, enquanto relação de imputação derivada da auto-referencialidade: depois de observar o entorno e suas demandas, bem como a si mesmo e sua capacidade estrutural para redução da complexidade, o sistema seleciona aqueles ruídos (perturbações ou irritações) que serão recebidos e considerados como informação (aqueles dados que são reconhecidos pelo sistema como distinções segundo o código de programação binário) apta a gerar novas estruturas capazes de reduzir a complexidade externa. 12

Portanto, denota-se que, de acordo com a teoria sistêmica, o direito é aberto e fechado, simultaneamente, permitindo que haja estimulação do meio, sem, contudo, manter contato direto com ele, o sistema do direito apenas observa e conhece as irritações externas sendo que suas operações internas se limitam a sua própria rede operacional, ou, sua própria estrutura. 9 JUNIOR, Luiz Cláudio Moreira Melo. A Teoria dos Sistemas Sociais em Niklas Luhmann. Soc. Estado. Vol.
28. N³. Brasília. Set/Dez. 2013.

10 LUHMANN, N. O conceito de sociedade. In: NEVES, C. B. ; SAMIOS, E. M. B. (Org.). Niklas Luhmann: a nova teoria dos sistemas. Porto Alegre: Ed. UFRGS,1997.

11 PAIM, Eline Luque Teixeira. Luhmann: o direito como sistema autopoiético. Conteúdo Jurídico. Nov. 2014.

12 Cfr. em LUHMANN, Niklas. Sociedade y sistema: laambición de lateoría, pp. 57,58,78 e ss, 98-106; IDEM. LUHMANN, Niklas. Introducción a lateoría de sistemas, pp. 96 e ss; IDEM. La ciência de lasociedad, pp.55 e ss. 
Maturana ${ }^{13}$ um dos propositores do pensamento sistêmico, a fim explicar o paradoxo entre ambiente e sistema, trouxe, pois, o conceito de acoplamento estrutural, que possibilita a simultaneidade de eventos entre o sistema e o meio.

Não há se confundir o acoplamento estrutural com a intervenção do meio no sistema, muito pelo contrário, o sistema, ainda que aberto a estímulos, permanece fechado, suficiente em si mesmo, conforme leciona Luhmann: “(...) não pode haver nenhuma contribuição do meio capaz de manter o patrimônio de autopoiesis de um sistema. O meio só pode influir causalmente em um sistema no plano da destruição. "14

O sistema deve selecionar aquilo que pode ser importante para sua estrutura interna, sem que a vontade do meio à modifique, ou seja, prevalece a vontade do sistema frente a do ambiente. 15

Disso resulta que, quando contextualizamos a Reforma da Previdência, tal como proposta pelo executivo, com a Teoria dos Sistemas Sociais, depara-se com a incongruência que seria permitir que os direitos fundamentais e sociais, conquistados, a muito custo, no âmbito previdenciário, fossem extintos e reduzidos ao patamar de índole econômica apresentado junto ao texto da citada Proposta.

Isso porque, como já dito, a PEC 287/2016 foi elaborada sob a justificativa de que a Previdência Social é deficitária e, por este motivo, seria a principal, senão a única, vilã dos problemas econômicos do país.

Nessa esteira, há uma tentativa de violação da característica autopoiética do direito, pois o sistema do Direito Previdenciário ${ }^{16}$ está sendo diretamente relacionado com o meio, o

13 MATURANA, Humberto R.; VARELA, Francisco J. Autopoiesis: The organization of living systems, its characterization and a model, Biosystems 5:187-196, 1974.

14 GONÇALVES, G. L. \& VILLAS BÔAS FILHO, O. Teoria dos sistemas sociais: direito e sociedade na obra de Niklas Luhmann. São Paulo, Saraiva; 2013.

15 PEREIRA, Geailson Soares. O Direito como Sistema Autopoiético. Revista CEJ, Brasília, out/dez/2011, ano XV, n. 55. p. 86-92

16 O Direito Previdenciário é um subsistema do Direito, pois, conforme a teoria de Luhmann, os sistemas são divididos em subsistemas cada vez mais especializados.

Segundo Moacyr Velloso Cardoso de Oliveira, o Direito Previdenciário se trata de um: "Conjunto de princípios e normas jurídicas destinadas a proteger os que exercem atividade remunerada e seus dependentes e, em certos casos, toda a população, nos eventos previsíveis de suas vidas, geradores de necessidades vitais, mediante uma organização criada pelo Estado, tendo como base econômica um sistema de seguro obrigatório, visando a realização da Justiça Social."

LUHMANN, Nikles. Introducción a lateoría de sistemas. Lecciones publicadas por Javier Torres Nafarrete. Guadalajara: Barcelona: Anthropos, 1996.

OLIVEIRA, Moacyr Velloso Cardoso de. Previdência Social. Rio de Janeiro, Freitas e Bastos;1987, p.50 
ambiente (Sistema Econômico) está tentando atingir sua estrutura interna. O ambiente está a tentar uma operação interna no Direito.

No conceito de Luhmann, não seria a vontade do sistema se sobrepondo ao meio, mas a vontade do meio prevalecendo sobre o sistema, e, conforme já mencionado, “o meio só pode influir em um sistema no plano da destruição."

A destruição, tal como descrita por Luhmann, não aparenta se tratar da erradicação do sistema, que permanecerá inserido na sociedade, entretanto, tende a descrever a desfuncionalidade do sistema, ou, em outras palavras, o sistema deixa de existir para aquilo que foi criado e passa a ocupar um lugar meramente figurativo na sociedade.

E não há dúvidas de que o Direito se trata de um sistema autopoiético:

“(...) o direito é sim um sistema autopoiético por vários motivos. Como sabemos, o sistema jurídico seleciona com suas estruturas somente aquilo que for relevante para suas operações internas.

Desse modo, ele é um sistema fechado pelo fato da a autopoiesis ser responsável pela sua autorreprodução e de o código binário não permitir que ruídos entrem no sistema. Em outras palavras, estruturas externas não produzem o direito.

(...)

Logo, se o sistema jurídico é paradoxalmente fecado normativamente, aberto cognitivamente e se reproduz a partir de suas próprias estruturas, não há como negar seu caráter autopoiético." 17

É, portanto, no mínimo, uma violação da regra da autopoiése a Proposta de Reforma da Previdência, mormente, considerando a busca pelo equilíbrio macroeconômico. Em outras palavras, o intuito da PEC não possui relação alguma com o direito em si, se trata de mera provocação do meio para alcançar uma finalidade financeira.

De resto, o direito previdenciário é um direito de $2^{\mathrm{a}}$. geração e, indiscutivelmente, fundamental para atingir os objetivos do Estado, previstos no art. 3, III da Constituição Federal, sendo que sua limitação de cobertura ou extinção significaria um grande retrocesso.

\section{MODELO CHILENO}

O jornalista Rocío Montes, do jornal global "El País”, explica, resumidamente, qual é a situação atual da previdência chilena. ${ }^{18}$

17 PEREIRA, Geailson Soares. O Direito como Sistema Autopoiético. Revista CEJ, Brasília, out/dez/2011, ano XV, n. 55. p. 86-92

18 MONTES, Rocío. Modelo pioneiro de previdência privada adotado no Chile enfrenta crise. El país, 18/02/2017. Disponível em: < $\underline{\text { http://brasil.elpais.com/brasil/2017/01/17/internacional/ }}$ 1484673838_832258.html> Acesso em: 04/03/2017 
A previdência Chilena foi privatizada em 1981 pelo ditador Augusto Pinochet. Hoje os trabalhadores são obrigados, por meio do desconto em folha, a reservar 10\% de sua renda para a aposentadoria. Os homens se aposentam aos 65 anos e as mulheres aos 60 .

As Administradoras de Fundo de Pensão (AFP) são responsáveis pelo gerenciamento das contribuições através do investimento junto à bolsa de valores, com o objetivo de obter rentabilidade.

O segurado pode escolher para qual fundo verterá a contribuição, cada fundo varia conforme o risco e quando se aposentar receberá uma pensão calculada com base na sua poupança individual. Por isso, 91\% (noventa e um por cento) da população chilena percebe menos que o salário mínimo. Também não se fala em aportes ou solidariedade dos trabalhadores ativos para com os aposentados. 19

Conforme abordado pelo jornal El País ${ }^{20}$, de acordo com um relatório feito por especialistas da Comissão Bravo, enviado à presidente Bachelet, o modelo está longe de ser perfeito, eis que sequer utiliza o princípio da contraprestação já que os benefícios percebidos são, no máximo, equivalentes a 45\% (quarenta e cinco por cento) do efetivo contribuído. Há uma evidente oneração excessiva ao segurado que, por sua vez, também fica à mercê dos investidores. ${ }^{21}$

A Previdência Chilena serve como plano de trabalho, o qual ora se adota, para toda comunidade global, tanto quanto a pontos negativos, como positivos.

O modelo chileno de previdência é constantemente apontado como exemplo por importar em grande economia para os cofres públicos, sendo considerado relativamente

19 GONÇALVES, G. L. \& VILLAS BÔAS FILHO, O. Teoria dos sistemas sociais: direito e sociedade na obra de Niklas Luhmann. São Paulo, Saraiva; 2013.

20 MONTES, Rocío. Modelo pioneiro de previdência privada adotado no Chile enfrenta crise. El país, 18/02/2017. Disponível em: <http://brasil.elpais.com/brasil/2017/01/17/internacional/ 1484673838 832258.html $>$ Acesso em: 04/03/2017.

${ }^{21}$ GONÇALVES, G. L. \& VILLAS BÔAS FILHO, O. Teoria dos sistemas sociais: direito e sociedade na obra de Niklas Luhmann. São Paulo, Saraiva; 2013. 
exitoso por alguns economistas e advogados ${ }^{22}$, mas, as qualidades da modalidade residem, principalmente, na desburocratização pela privatização.

A medida que se desenvolvem estruturas burocráticas que peneiram os direitos dos segurados à miúde, o sistema tende a ser tragado pela própria sustentabilidade. $\mathrm{O}$ modelo chileno mostrou-se muito competente nesse mérito.

Porém também demonstrou um contraponto: a privatização, por sua natureza, permitiu que o privado explorasse o Estado e sua população, de tal modo que submeteu os segurados à percepção de valores irrisórios e inferiores ao salário mínimo vigente no país.

A intenção é seguir rumo à evolução dos direitos sociais e não a sua decapitação. Ao contrário do que pretende a Reforma da Previdência Brasileira, os direitos previdenciários devem ser manutenidos, eis que fazem parte dos objetivos da República.

Segundo publicado pela Folha de São Paulo ${ }^{23}$, apenas 4\% (quatro por cento) dos brasileiros poupam para aposentadoria; nessa linha, refere a planejadora financeira Maristela Gorayb $^{24}$ que os brasileiros não possuem cultura financeira e que a previdência privada é excelente para essa disciplina. Ocorre que tais afirmações vão de encontro a realidade brasileira, veja-se que quando se fala em cultura financeira há que se considerar a situação dos menos favorecidos, que não auferem o suficiente para o próprio sustento e de sua família ou que estão passando por uma situação que os impedem de economizar.

A previdência Chilena é cruel nesse sentido, não há qualquer benefício para quem não contribui e a contribuição é obrigatória para quem trabalha.

22 DYNIEWICZ, Luciana. Após Protestos, Chile Busca Soluções para a Previdência. Folha de São Paulo, 14/08/2016. Disponível em: <http://www1.folha.uol.com.br/mercado/2016/08/1802709-apos-protestos-chilebusca-solucoes-para-a-previdencia.shtml> Acesso em: 23/03/2017.

LEITE, Pedro Henrique. Chile deve servir de Exemplo para Reforma Previdenciária Brasileira. Conjur, 18/01/2017. Disponível em: <http://www.conjur.com.br/2017-jan-18/pedro-leite-chile-exemplo-reformaprevidenciaria-brasil> Acesso em: 23/03/2017.

${ }^{23}$ PINTO, Ana Estela de Sousa. Apenas 4\% dos Brasileiros Poupam para a Aposentadoria. Folha de São Paulo, 08/01/2017. Disponível em: <http://www1.folha.uol.com.br/mercado/2017/01/1847930-apenas-4-dosbrasileiros-poupam-para-a-aposentadoria.shtml $>$ Acesso em: 16/03/2017

24 SILVA, Liz. Falta Cultura Financeira nos Brasileiros - diz Especialista em Previdência. Infomoney, 29/09/2015. Disponível em: <http://www.infomoney.com.br/onde-investir/previdencia/noticia/4311318/faltacultura-financeira-nos-brasileiros-diz-especialista-previdencia $>$ Acesso em: 16/03/2017 


\section{Carlos Ominami Pascual25, presidente da Fundação Chile21, refere que a previdência} chilena se revelou um fracasso e um exemplo do que o Brasil deve evitar. Segundo ele:

O melhor do sistema de previdência chileno é seu marketing internacional. Foi amplamente publicizado não por suas virtudes, mas por ser um negócio. A propaganda foi incrível, tanto na ditadura como na democracia, onde altas fontes nacionais saiam ao mundo a promover o sistema. Uma vergonha! Sempre afirmei que se tratava de financiamento de empresas com a economia dos trabalhadores usando um sistema de seguridade social. A seguridade não pode ser sistema onde se tem a pura capitalização individual $\mathrm{e}$, se acaba o fundo, o que pode ocorrer se a pessoa viver mais do que o sistema determina que ela possa viver. [...]

As pessoas terão na aposentadoria tanto quanto forem capazes de acumular. Se for um trabalhador estável, com bom emprego e bom salário desde o princípio, boa saúde e trabalhar 40 anos, o sistema responde. A questão é que apenas $10 \%$ está nesta situação. A maioria tem uma curva instável, acumula pouco, a taxa de retorno, que se prometeu de cerca de $70 \%$ quando se implantou, hoje é menos de $40 \%$ e faz com que as pessoas tenham pânico de se aposentar. É a preocupação número um das pessoas. As grandes mobilizações do Chile não são mais por educação, mas por previdência.

Para Carlos ${ }^{26}$, será mais fácil resistir a Reforma Previdenciária no Brasil, pois hoje há

parâmetros para contestá-la. Segundo ele, toda e qualquer mudança que se pretenda deve respeitar os princípios da seguridade social, em suas palavras:

[...] Não é admissível que um pobre, sem educação, seja condenado a pobreza extrema quando envelhece. Isso não é seguridade e não pode ser tolerado. É preciso um princípio de solidariedade, como funciona a sociedade, onde os ricos ajudam os pobres, os saudáveis ajudam os doentes e os jovens ajudam os velhos. Defendo um sistema único, homogeneizado, entendendo que nem todos os trabalhos são iguais e há ofícios diferentes que devem ser levados em conta pelo nível de esforço e exigência - não há como comparar os que trabalham em minas ou nos escritórios. É preciso estabelecer diferenças justas, não privilégios. E tem que haver prêmio para o esforço individual, e não repartir igualmente $100 \%$ porque pode haver gente que não queira trabalhar e se beneficiar indevidamente. Isto gera justas resistências em quem paga. Acho que um sistema misto pode ser uma solução. Dos que conheço, acho interessante a Escandinávia: há capitalização individual, há solidariedade, e fundos bem administrados que competem entre si. Na Suécia também há sistema misto, com capitalização individual e o Estado centraliza todas as cotizações e distribui as administradoras para ver quem melhor rentabiliza o fundo.

$\mathrm{O}$ modelo chileno de previdência aumentou a distância entre as classes sociais e fracassou em seu objetivo principal "a seguridade social”. De outro modo, a previdência chilena foi um sucesso, trouxe grande economia para os cofres públicos, de tal modo que é

25 PASTORE, Stela. O Fracasso do Sistema Chileno de Previdência. Fórum das Resistências. Extraclasse, 01/2017. Disponível em: < http://www.extraclasse.org.br/exclusivoweb/2017/01/o-fracasso-do-sistema-chilenode-previdencia/ $>$ Acesso em: 16/03/2017

26 PASTORE, Stela. O Fracasso do Sistema Chileno de Previdência. Fórum das Resistências. Extraclasse, 01/2017. Disponível em: < $\underline{\text { http://www.extraclasse.org.br/exclusivoweb/2017/01/o-fracasso-do-sistema-chileno- }}$ de-previdencia/ $>$ Acesso em: 16/03/2017 
frequentemente e até hoje elogiada. Conforme referido por Pedro Henrique Leite ${ }^{27}$ : “(...) $O$ êxito do sistema chileno é incontestável em termos de retorno pois ele oportuniza uma rentabilidade de mais de 9\% acima da inflação. (...)”

Ocorre que a previdência não pode ser vista somente como uma questão financeira e a beneficiar as contas estatais, ou seja, o Sistema do Direito Previdenciário, em conjunto com todos seus princípios e objetivos, não pode ser alterado/confundido pelo Sistema da Economia, sob pena de se tornar sem propósito, desfuncional, sob pena de destruição.

A solução proposta - buscando o equilíbrio das contas - para o problema brasileiro seria o desenvolvimento de medidas alternativas que objetivem a diminuição do custo de manutenção da própria estrutura da previdência. Entretanto, sem se falar em privatização.

Um exemplo disso seria focar na Previdência Social como entidade fiscalizadora, tornando-a eficaz nesse sentido, permitindo que se utilize menos servidores para avaliação de requerimentos, pois pela eficiência da fiscalização o cadastro de contribuições e demais dados dos segurados presumir-se-ão corretos. Não olvidando que, melhorando a fiscalização, a consequência seria o aumento da arrecadação.

Com uma fiscalização eficiente a burocracia existente para análise de requerimentos, que demoram meses e, não poucas vezes, anos, para serem concluídos, passa a ser obsoleta para o sistema.

Nesta linha, outro exemplo seria desenvolver um convênio entre o Sistema Único de Saúde e a Previdência Social. Afinal, quando o segurado passa pela avaliação médica do SUS está, indiretamente, sob o crivo de um profissional legítimo e oficial da Seguridade Social, sem que necessite ser submetido a nova avaliação ou se deslocar a uma Agencia da Previdência Social para ser atendido, bastando o envio do Laudo SABI28, devidamente preenchido, pelo médico ao INSS.

Logo, existem soluções que podem ser estudadas no lugar de se limitar ou extinguir direitos conquistados ao longo de anos, também em respeito à vedação do retrocesso social.

27 LEITE, Pedro Henrique. Chile deve Servir de Exemplo para a Reforma Previdenciária Brasileira. Conjur, 18/01/2017. Disponível em: <http://www.conjur.com.br/2017-jan-18/pedro-leite-chile-exemplo-reformaprevidenciaria-brasil $>$ Acesso em: 17/03/2017

28 Sistema de Administração de Benefícios por Incapacidade: módulo de atendimento - Realiza a Perícia Médica - utilizado nas APS e pela Internet. Disponível em: $<$ http://www3.dataprev.gov.br/sabi/apresentacao.htm $>$ Acesso em: 25/03/2017. 


\section{CONCLUSÃO}

Através do presente estudo, restou verificado que a Reforma da Previdência se trata de uma tentativa do meio de irritar a estrutura interna do subsistema do direito previdenciário. Caso isso ocorra, a consequência seria catastrófica, pois, pela Teoria Sistêmica, o meio só pode influir causalmente em um sistema no plano da destruição.

A destruição, tal como descrita, não significa o desaparecimento do sistema, mas sim, a sua desfuncionalidade, o direito previdenciário passaria então a se tratar de uma denominação figurativa para a sociedade, sem, no entanto, cumprir os objetivos pelo que foi criado/desenvolvido.

Assim, passariam de cidadãos efetivamente acobertados pelo seguro social, em harmonia com as previsões constitucionais, com os direitos fundamentais e os objetivos fundamentais da República, para cidadãos figurativamente acobertados pelo seguro social, em contradição às previsões constitucionais, de encontro aos direitos fundamentais e objetivos fundamentais do Estado.

Nesse desiderato, a hipótese levantada fora extraída do direito comparado. A tão polêmica Previdência Chilena traz elementos positivos e negativos que devem ser considerados por todos os países quando da intenção de propor reformas previdenciárias.

O modelo Chileno é sinônimo de grande economia para os cofres públicos. Entretanto, em termos de cobertura, pelo sistema ter sido corrompido, está causando um caos entre os chilenos. Assim sendo, a previdência não pode ser vista sob uma índole econômica, sob pena de ferir a Carta Magna e, inclusive, Tratados Internacionais de que o Brasil faz parte.

Veja-se que a Previdência Chilena sofreu uma desburocratização em função da privatização. Essa desburocratização resultou em maior economia para sustentar a própria estrutura previdenciária.

A medida alternativa para o Brasil seria implementar um programa de desburocratização voltado para a estrutura das próprias agências de previdência social, através de um sistema de fiscalização mais efetivo que seja capaz de dispensar a análise documental e a demora de meses ou anos para a conclusão do requerimento de benefício.

Em outras palavras, seria fazer da Previdência Social uma autarquia essencialmente de fiscalização - o que, inclusive, aumentaria a arrecadação - que importaria num acervo de 
dados dos segurados mais justo, dispensando a análise física de documentos e, quem sabe, até o atendimento presencial.

A acentuação do dever de fiscalização, por si só, já traria uma arrecadação maior e isso somado a diminuição da burocracia em decorrência do acerto das informações constantes nos bancos de dados pela fiscalização, significaria a sustentabilidade da seguridade social.

\section{REFERÊNCIAS BIBLIOGRÁFICAS}

BRASIL. Constituição da República Federativa do Brasil de 1988. Brasília. Disponível em: $\leq$ http://www.planalto.gov.br/ccivil_03/constituicao/constituicao.htm $>$ Acesso em:

Lei $n^{\circ}$ 8.213, de 24 de julho de 1991.Dispõe sobre os Planos de Benefícios da Previdência Social e dá outras providências. Disponível em: $<\underline{\text { http: } / / \text { www.planalto.gov.br } /}$ ccivil_03/leis/18213cons.htm Consulta a Lei 8.213/91>. Acesso em: 01/09/2014.

BALERA, Wagner. Sistema de Seguridade Social. 3. ed. São Paulo: LTr, 2003.

GONÇALVES, G. L. \& VILLAS BÔAS FILHO, O. Teoria dos sistemas sociais: direito e sociedade na obra de Niklas Luhmann. São Paulo, Saraiva; 2013.

HORVATH, Miguel. Direito Previdenciário. 5. ed. São Paulo: QuartierLatin, 2005.

JUNIOR, Luiz Cláudio Moreira Melo. A Teoria dos Sistemas Sociais em Niklas Luhmann. Soc. Estado. Vol. 28. No3. Brasília. Set/Dez. 2013.

KeRTZMAN, Ivan. Curso Prático de Direito Previdenciário. 8. ed. Salvador: Juspodivm, 2011.

LUHMANN, N. O conceito de sociedade. In: NEVES, C. B. ; SAMIOS, E. M. B. (Org.). Niklas Luhmann: a nova teoria dos sistemas. Porto Alegre: Ed. UFRGS,1997.

Introdução à Teoria dos Sistemas. Petrópolis: Editora Vozes, 2009 (1995);

Introducción a lateoría de sistemas. Lecciones publicadas por Javier Torres Nafarrete. Guadalajara: Barcelona: Anthropos, 1996.

MATURANA, Humberto R.; VARELA, Francisco J. Autopoiesis: The organization of living systems, its charac-terization and a model, Biosystems 5:187-196, 1974.

OLIVEIRA, Moacyr Velloso Cardoso de. Previdência Social. Rio de Janeiro, Freitas e Bastos; 1987.

PAIM, Eline Luque Teixeira. Luhmann: o direito como sistema autopoiético. Conteúdo Jurídico. Nov. 2014. 
PEREIRA, Geailson Soares. O Direito como Sistema Autopoiético. Revista CEJ, Brasília, out/dez/2011, ano XV, n. 55.

ALEGRetTI, Laís. Reforma da Previdência pode gerar economia de R\$ 678 bi, diz governo. Folha de São Paulo, 05/12/2016. Disponível em: <http://www1.folha.uol.com.br/ mercado/2016/12/1838400-reforma-da-previdencia-pode-gerar-economia-de-r-678-bi-dizgoverno.shtml> Acesso em: 20/01/2017.

BONFATTI, Cristiane et al. Ajuste só estará completo com reforma da Previdência, afirma Temer. Valor Eco-nômico, 21/11/2016. Disponível em: <http://www.valor.com.br/politica/ 4782125/ajuste-so-estara-completo-com-reforma-da-previdencia-afirma-temer $>$ Acesso em: 23/03/2017.

DYNIEWICZ, Luciana. Após Protestos, Chile Busca Soluções para a Previdência. Folha de São Paulo, 14/08/2016. Disponível em: <http://www1.folha.uol.com.br/mercado/ 2016/08/1802709-apos-protestos-chile-busca-solucoes-para-a-previdencia.shtml $>$ Acesso em: 23/03/2017.

INSS. Sistema de Administração de Beneficios por Incapacidade: módulo de atendimento Realiza a Perícia Médi-ca - utilizado nas APS e pela Internet. Disponível em: <http:// www3.dataprev.gov.br/sabi/apresentacao.htm> Acesso em: 25/03/2017.

LEITE, Pedro Henrique. Chile deve Servir de Exemplo para a Reforma Previdenciária Brasileira. São Paulo. Consultor Jurídico, 18/01/2017. Disponível em: <http:// www.conjur.com.br/2017-jan-18/pedro-leite-chile-exemplo-reforma-previdenciaria-brasil> Acesso em: 17/03/2017

MONTES, Rocío. Modelo pioneiro de previdência privada adotado no Chile enfrenta crise. El país, 18/02/2017. Disponível em: <http://brasil.elpais.com/brasil/2017/01/17/internacional/ 1484673838_832258.html > Acesso em: 04/03/2017

OLIVEIRA, Gesner. Sem reforma da previdência não há ajuste fiscal. Uol Economia, 31/01/2017. Disponível em: <http://gesneroliveira.blogosfera.uol.com.br/2017/01/31/semreforma-da-previdencia-nao-ha-ajuste-fiscal/> Acesso em: 23/03/2017.

PASTORE, Stela. O Fracasso do Sistema Chileno de Previdência. Extraclasse, 01/2017. Disponível em: <http://www.extraclasse.org.br/exclusivoweb/2017/01/o-fracasso-do-sistemachileno-de-previdencia/> Acesso em: 16/03/2017

PINTO, Ana Estela de Sousa. Apenas 4\% dos Brasileiros Poupam para a Aposentadoria. Folha de São Paulo, 08/01/2017. Disponível em: <http:/www1.folha.uol.com.br/mercado/ 2017/01/1847930-apenas-4-dos-brasileiros-poupam-para-a-aposentadoria.shtml $>$ Acesso em: $16 / 03 / 2017$

SILVA, Liz. Falta Cultura Financeira nos Brasileiros - diz Especialista em Previdência. Infomoney, 29/09/2015. Disponível em: <http://www.infomoney.com.br/onde-investir/ previdencia/noticia/4311318/falta-cultura-financeira-nos-brasileiros-diz-especialistaprevidencia> Acesso em: 16/03/2017 